\title{
Characteristics of Effective Collaboration in Response to Diversified Transportation Planning Authority
}

\author{
John S. Miller \\ Virginia Center for Transportation Innovation and Research, 530 Edgemont Road, Charlottesville, \\ Virginia 22903, USA \\ Correspondence should be addressed to S. John Miller, john.miller@vdot.virginia.gov
}

Received 17 December 2010; Revised 25 May 2011; Accepted 4 July 2011

Academic Editor: Andreas Soteriou

Copyright (C) 2011 S. John Miller. This is an open access article distributed under the Creative Commons Attribution License, which permits unrestricted use, distribution, and reproduction in any medium, provided the original work is properly cited.

\begin{abstract}
Advantages of decentralized transportation planning responsibilities may include reduced project delivery cost, the integration of comprehensive long-range planning with regional land use, and greater accountability regarding local concerns. Yet disadvantages may include a tendency for operations to dominate longer-term planning, inconsistent operational standards, and difficulty in achieving network benefits, since some transportation links may provide benefits to the entire system but not to the immediate area where the link is located. To surmount these challenges in a decentralized environment, agencies need to cooperate effectively. Characteristics of effective collaboration include (1) experienced personnel, (2) credibility of the deciding entity, (3) transparency of decision-making processes, (4) an authority with sufficient power and/or funding to encourage implementation of key initiatives, (5) clear incentives for cooperation, and, of special importance given limited resources, and (6) an ability to evaluate tradeoffs. An access management case study demonstrates how agencies may use these characteristics to advance challenging projects in a decentralized environment.
\end{abstract}

\section{Introduction}

Transportation investments are chosen by several types of entities: interstate coalitions, state departments of transportation (DOTs), regional entities such as metropolitan planning organizations [MPOs], and individual cities and counties. Transportation planning responsibilities may shift among this hierarchy of organizations over time such that decisions rest with a more centralized level (e.g., an interstate coalition) or a more decentralized level (e.g., a locale). 
Such reallocation of responsibilities may result from altered public perceptions regarding which entity is best poised to distribute scarce resources. For example, with respect to programming specific projects, the Congressional Research Service (CRS) suggested that MPO programming authority should be expanded, given MPOs' ability to consider problems that cross jurisdictional boundaries [1]; others have argued against such an expansion, giving the rationale that MPOs place too great an emphasis on behaviors not necessarily desired by constituents [1,2]. Lewis and Sprague [3] questioned whether an MPO should be an umbrella organization that devolves some authority to member counties or whether the MPO should be a strong, centralized regional entity in its own right.

Virginia has experimented with decentralizing decision authority from the state DOT to the individual locale. Legislation enacted in 2001 (\$ 33.1-84.1 of the Code of Virginia) allows counties to assume responsibility for secondary road functions previously performed by the state, although, at this point, no county has decided to participate. The Virginia Department of Transportation's (VDOT) Urban Construction Initiative allows localities to manage construction projects within their city or town borders even if projects are state or federally funded. As of 2009, 10 jurisdictions had elected to participate [4]. Such results are not unusual: Canning et al. [5] reported that transportation powers devolved to England's Local Transportation Authorities have been exercised to a limited degree, partly because of competing priorities such as economic development.

Clearly attitudes differ regarding where transportation decision authority is best situated. Since such viewpoints, and the commensurate responsibilities granted to individual organizations, may change hierarchical levels, long range planners may be well served by examining lessons learned by organizations that have experimented with shifting such authority.

\section{Purpose}

The purpose of this paper is to determine how individual organizations can respond to organizational shifts in transportation decision-making authority. A motivation was to support Virginia's statewide multimodal plan [6]. Accordingly, this paper has three research objectives:

(i) identify how institutional decision-making authority may evolve [7] by 2035,

(ii) synthesize lessons learned regarding how organizations can effectively collaborate in a decentralized environment,

(iii) demonstrate the application of these lessons with a case study.

The case study contributes to the literature in that it shows steps an agency can take even when that agency lacks direct decision authority.

\section{Methodology}

Three steps comprised the methodology used to develop this paper.

\section{(1) Conduct a Literature Review}

The literature suggesting how decision-making processes have changed provided a context for defining planning's role within each organization. Then, a specific type of planning 
responsibility—the programming of transportation projects-was examined in ten states where documentation was readily available: California, Florida, Iowa, Kansas, Maryland, Missouri, Nevada, New Jersey, North Carolina, and Virginia. Programming (i.e., the establishment of a schedule of specific investments [8]) is not the same as planning (i.e., the provision of relevant information to decision makers [9]), but the relationship of the two necessitates their joint consideration. This latter part of the review examined how transportation programming authority is allocated between the state and MPO level.

\section{(2) Synthesize from the Literature the Cited Strengths and Weaknesses of Various Decision-Making Processes}

Emphasis was placed on the rationale given for locating decision-making authority at the local, regional, and multistate levels of government in contrast to the state level of government. Best practices were documented.

\section{(3) Apply the Lessons Learned to a Case Study of Interest}

One topic of interest concerns how the state can encourage access management in an environment where localities, rather than the state, operate secondary facilities. The characteristics of effective cooperation, gleaned from steps 1 and 2, were used to identify ways such encouragement might occur despite a lack of state authority.

\section{The Literature Review}

\subsection{Shifts of Decision-Making Powers}

Decision-making powers may shift from states to three administrative levels: multistate coalitions, MPOs, and localities.

\subsubsection{Authority Shifts to Multistate Coalitions}

Multistate partnerships have been suggested as essential for achieving a particular transportation goal. In response to insufficient national funding, Roth and Aggarwala [10] advocated forming a multistate partnership to support passenger rail service from Boston to Washington, DC. Such multistate areas, also known as megaregions [11], will alter planning processes in several ways, such as the use of a longer planning horizon and the use of a tiered planning process where planning is conducted at multiple levels of government (e.g., the traditional metropolitan planning process coupled with planning for multistate initiatives [11]).

East Coast examples show decision authority being shifted to the multistate level. In the corridors of the future program, five states-Florida, Georgia, North Carolina, South Carolina, and Virginia-will coordinate improvements along the I-95 corridor [12, 13]. The Federal Highway Administration (FHWA) will distribute $\$ 21.8$ million, which the states will use to pursue three discrete endeavors: (1) consider the use of public-private partnerships to minimize construction costs, (2) develop a consistent approach to intelligent transportation system projects, and (3) develop consistent performance measures based on travel time and reliability. The I-81 multistate corridor initiative is another interstate coalition; Maryland, New York, Pennsylvania, Tennessee, Virginia, and West Virginia signed a memorandum of understanding [14]) to collaborate on highway and rail improvements. 


\subsubsection{Authority Shifts to MPOs}

A US House of Representatives' proposal for the next federal surface transportation authorization program specified that MPOs larger than 1 million people must develop performance metrics relating to housing supply for all income levels, land use patterns supporting reduced single-occupant autotrips, and water conservation $[15,16]$. Such indices are consistent with the suggestion by Amekudzi et al. [11] that in very large areas, the manner in which transportation performance is assessed will include "congestion indices, air quality, safety, relocation desirability for businesses, and quality of public health." The proposed legislation also established an extra source of funds available to MPOs serving an urbanized area in excess of one-half million people [17]. (The outcome of this legislative proposal is uncertain; its existence simply suggests interest in altering decision authority.) Puentes and Bailey [18] identify broader land use considerations as another reason for giving MPOs greater programming authority.

\subsubsection{Authority Shifts to Localities or Other Regional Entities}

Apart from states and MPOs, regional decision making has been accomplished through creating local or regional authorities. Examples are county metropolitan authorities in California (funded by up to a 1 cent sales tax) and San Diego's Transnet program (a regional authority using a $1 / 2$ cent sales tax to fund a $\$ 14$ billion (40 year) transportation program, with funding split three ways for regional freeways, transit, and localities [19]). The Virginia Railway Express (VRE) is owned and operated by two transit-oriented commissions: the six-jurisdiction Northern Virginia Transportation Commission and the five-jurisdiction Potomac and Rappahannock Transportation Commission [20]. Each regional entity exists to achieve a specific objective (e.g., in the case of VRE, the provision of commuter rail service).

\subsection{How a Subset of States Allocate Transportation Programming Authority}

Federal law requires that the Transportation Improvement Program (TIP)—-the MPO's program of regionally significant federally funded projects-be developed and approved by the MPO and be "incorporated directly, without change" into the Statewide TIP (STIP) [21]. Such language implies MPOs have primary authority to select projects. However, this authority varies by state, with categorizations loosely described as follows.

\subsubsection{Strong Local and MPO Influence: California}

Nominally, California's MPOs have substantial programming authority with respect to state funds. MPOs and regional transportation planning agencies, which are created for areas that are too small to have an MPO, control 75\% of the state TIP funds, with the state controlling the remaining 25\% [22]. Yet two limitations, and one enhancement, to MPO authority exist.

(i) MPOs May Further Devolve This Authority to Locales Either by Requirement or by Choice

California's Senate Bill 45 devolves Congestion Mitigation and Air Quality (CMAQ) and Surface Transportation Program (STP) funds (for MPOs that have "air quality troubles") to individual counties; further, the Los Angeles MPO devolves programming authority 
to its member counties [23]. For another California MPO (Association of Monterey Bay Area Governments), the individual county transportation commissions program state funds whereas the MPO programs federal funds [22]. Cambridge Systematics [24] indicated that the Metropolitan Transportation Commission (MTC) (the MPO for the nine-county San Francisco Bay Area) "suballocates its funding to the county agencies and these agencies submit projects to be included" in the regional transportation plan. Project evaluations conducted by MTC are then considered by counties, leading the authors to note that most programming for transportation infrastructure "occurs at the county level" [24].

\section{(ii) Other Funding Sources May Grow}

The MPO role appears to be diminished given that individual counties can levy up to an additional 1\% increase in sales tax for transportation infrastructure, and 19 counties have elected to increase their sales tax accordingly [25]. Locally approved " $1 / 2$ cent sales tax measures" [22] for transportation infrastructure are a greater source of transportation revenue than the combination of state and federal sources for new investments and require a referendum with approval by two-thirds of the county voters.

\section{(iii) The Role of MPOs Appears to Be Enhanced}

Given that California MPOs are required to assist with project delivery, this responsibility is accentuated by the requirement that (1) projects be awarded within 12 months of funds being allocated to the project and (2) projects be completed, and all funds be spent within 36 months of the award [26].

\subsubsection{State Influence: Iowa, Kansas, Maryland, Missouri, North Carolina, and Virginia}

Although MPOs have influence, each state plays a strong role in TIP's project selection. For example, the North Carolina TIP is a "consultative process between the North Carolina DOT and the 37 regional planning organizations" with a role for the DOT being to "share project selection with MPOs" and with a role for MPOs being to "develop and share project selection with NCDOT" [27].

Iowa's STIP is developed each year via a "cooperative effort" [28] between the state DOT, its nine MPOs, and 18 regional planning affiliations. MPOs have direct authority over STP funds and one-half of "of the state's 10 percent STP apportionment for transportation enhancement projects" [28]. Aside from the STP, transportation enhancements and transit projects, other projects that appear in the TIP's are provided to the MPO or the Regional Planning Association [28].

Goode et al. [29] reported that substantial decision authority is located within the Missouri and Kansas "highway priorities subcommittees" for the Mid-America Regional Council (MARC), the Kansas City MPO, noting that Kansas-based projects receive funding only if they appear on two lists: the STIP and a "local projects list." Thus Kansas appears to provide some projects for the MPO to include in its TIP. By contrast, Missouri gives the MPO a greater amount of programming authority, with MARC apparently being able to program projects using a given funding formula of $40 \%$ for capacity improvements, $40 \%$ for maintenance, and $20 \%$ for operations [29].

A "consultative" process between the Maryland DOT and Maryland's counties (plus Baltimore City) finalizes the STIP, which is then used to create the TIP for each of Maryland's 
six MPOs [30]. For MPOs of less than 200,000, the DOT plays a primary role in project selection. For example, regarding the TIP for the multistate Hagerstown-Eastern Panhandle MPO, MDOT has "final responsibility" for selecting projects for the Maryland portion of the MPO [31]:

Most Virginia programming is performed by the Commonwealth Transportation Board. Depending on air quality attainment status and population level, MPOs may be solely responsible for programming a relatively small component of these projects: those that are funded with CMAQ funds or Regional Surface Transportation Program (RSTP) funds.

\subsubsection{Shared Influence: Florida, Nevada, and New Jersey}

Certainly all states' processes may be described as sharing influence, since the TIP requires approval by both the state and the MPO. However, examples in Florida, Nevada, and New Jersey suggest some specific practices for sharing this decision authority.

Ayers [32] described TIP formation of Florida's Hillsborough County MPO as follows:

"First, the MPO adopts the TIP priorities. Second, FDOT develops a tentative program based on funding availability. Third, the MPO adopts the TIP including the FDOT statewide priorities. Finally, the STIP is approved by the state legislature."

When MPOs and local governments provide the Florida DOT districts a list of project priorities (which the districts must incorporate "to the maximum extent feasible") in their work program, the districts are required to explain to MPOs, in writing, the rationale for not including in their work program projects that are both part of the TIP and have been included in the work program for the past 4 years [33].

Nevada's MPOs develop the TIP in tandem with the state DOT [34]. The Regional Transportation Commission (RTC) (the Las Vegas MPO) has both operational and planning responsibilities. Since 2004, the RTC has operated the Freeway Arterial System of Transportation (FAST), thereby linking operations (e.g., the FAST traffic management system) with planning (e.g., the traditional transportation planning performed by the MPO) [35]. RTC's focus on implementation is not unique, given that some (37\%) MPOs implement transportation projects, and a smaller portion (16\%) operate, entirely or in part, a regional transit system [36].

The RTC "borrows" the taxing authority of the county with which it is almost perfectly aligned: the county collects taxes and is allowed to provide the revenues to the MPO, which the county does, and then the revenues are spent based on the MPO's long-range transportation plan [23]. A critical reason that this arrangement is feasible (in addition to being permitted by the state legislature) is that the geographic boundaries of the MPO align with the geographic boundaries of a key administrative unit (which in this case is the county since it collects the tax revenue).

New Jersey has used a three-phase system for selecting all capital projects in the TIP and the STIP [37]. During the screening phase, a meeting in each of the four geographical regions of the state is held between the New Jersey DOT staff and MPO staff where some projects were identified as feasible for placement in the TIP. During the prioritization phase, each MPO and the DOT use its own process to establish project priorities which is based on the prioritization scores from the MPOs and DOT and other factors such as the availability of funding by category. During the negotiation phase, the DOT, NJTransit, and the three MPOs establish and then follow a schedule for negotiations over which projects must go into the TIPs for the MPO. 


\subsubsection{Summary}

Although MPOs should enjoy substantial TIP project selection authority, this decentralization (relative to the state level) or centralization (relative to the local level) does not necessarily occur to the extent one might expect from a review of the regulations alone(see, e.g., $[1,38]$ ). In some instances, this authority is devolved by the MPO to the locale; in other instances, this authority remains centralized at the state level. Although one might characterize such decisions as a contrast between local and regional interests, it is noteworthy that several innovative cooperative mechanisms emerge. Examples of these are localities coordinating forces to achieve a common goal (California), enhanced transparency (New Jersey and Florida), and a linkage of MPO authority to existing institutional structures to leverage the county's taxing authority (Nevada). These mechanisms may be placed within a taxonomy of advantages and disadvantages of decentralizing other areas of transportation planning-related decision making, as the literature is somewhat divided regarding where authority should be placed.

\section{Synthesis: Advantages of Changes in Decision Making}

The placement of programming at a multistate, state, regional, or local level of government may be characterized as selection of the appropriate tier for decision making. The debate concerning whether local autonomy or centralized control is more beneficial is not new. A review of Ross et al. [39] suggests that the [centralized] Tennessee Valley Authority (TVA) and the [decentralized] Appalachian Regional Commission (ARC) may be contrasted in terms of their responsiveness to local needs and their ability to implement a regional goal. The TVA has a strong central authority providing power generation and land forestation but is less responsive to regional needs [39]. The ARC is more responsive to regional needs; it provides funding to 13 states for economic development but places less emphasis on achieving a unified vision; a criticism of which has been that "ARC-funded highway construction ... [lacks] ‥ a regional basis for coordinated development" [39]. This debate between local autonomy and a strong central authority also appears in transportation; even at the regional level, there is some debate as to whether an MPO should be a strong centralized authority, an administrative mechanism for coordinating local priorities, or some combination of the two [3].

\subsection{Perceived Advantages of Devolving Decisions to the Most Local Form of Government}

The literature cites advantages of devolving decisions to the most local form of government as follows.

\section{(i) Greater Efficiency Resulting from Local Project Administration}

Whitley [40] noted that Virginia's Urban Construction Initiative is beneficial because of a reduction in overhead costs; this reduction comes from reduced staff time and an ability to customize local solutions. Seefeldt et al. [41] noted that greater local involvement with project delivery could enable the use of certain processes by locales, such as the use of condemnation authority, to accelerate project delivery. 
(ii) Greater Ability to Link Planning with Operations or Land Use

Nevada's FAST (linking traffic management and transportation planning) has enabled the MPO to be more responsive to citizen suggestions (such as signal retiming) and to locally elected officials [35]. Minnesota's Metropolitan Council (the MPO for Minneapolis/St. Paul) has responsibility for operating bus service and light rail transit service as well as transportation planning [42]. Further, the MPO involves localities who directly control land development decisions [18].

\section{(iii) Greater Responsiveness}

The assumption is that local governments are more accountable to citizens than more centralized levels of government. Examples are "quick-take" condemnation authority that may be exercised by local governments [41], an ability to protect local neighborhoods from the threat of through truck traffic [43], and an ability for local staff to respond immediately to citizen complaints regarding a specific project [40]. A similar advantage was noted when decentralizing decision authority in an organization; a review of the Texas DOT noted that providing substantial authority to district offices (rather than centralizing decisions at the headquarters level) enabled a sharp customer focus and allowed for "timely and least expensive access, contact with the public, and knowledge of local conditions" [44].

\subsection{Perceived Disadvantages of Devolving Decisions to the Most Local Form of Government}

Yet the literature notes four disadvantages of devolving decisions to the most local form of government.

\section{(i) Loss of Network Benefits}

A transportation network reflects economies of scale that accrue from a series of interdependent connections. Giuliano [45] noted that the most recent reauthorization (SAFETEA-LU) "is a much weakened structure for stewardship of the National Highway System," citing the prevalence of earmarks and minimum percentages to states of donated highway funds. Yusuf et al. [46] suggested that objective indicators of need (e.g., volumes, road conditions, growth, and economic development impacts) are often "ambiguous or conflicting," which contributes to a situation where issues of local concern may be weighted more heavily than the "general interest." Mason [47] highlighted the value of MPOs, noting that "as local jurisdictions become major revenue sources, the potential for fragmentation or balkanization of state and regional transportation systems increases." Relative to localities, Mallet suggests that MPOs may be the best way, at present, to reduce "fragmentation" of planning-related decisions [1].

(ii) Projects Are Not Built without Full Mitigation of Adverse Impacts and Benefits for Each Entity

Whereas a single entity can presumably make a tradeoff between regional benefits and local disbenefits, the distribution of authority to a variety of smaller units means increases in the number of adverse impacts that must be addressed. Giuliano [45] cites Los Angeles' rail 
transit program: although only a few corridors could support rail transit, the decentralized structure of multiple jurisdictions and no strong regional authority meant that all jurisdictions needed some component of rail transit in order for a rail plan to move forward. Accordingly, Los Angles emerged with an overly ambitious plan that resulted in several lines with insufficient demand; further, when such lines are built, a larger subsidy than anticipated will be required. Further, a community may not have an incentive to invest in port improvements [48] even though such investments in capacity may reap national benefits. Consequently, the "last mile" (i.e., the connection between the National Highway System and the port) in some cases has taken over a decade to improve [48].

\section{(iii) Nonuniform Standards and Practices}

When the various components of a transportation system are managed by different decisionmaking entities, travelers may perceive variation in how the facility is operated. Bonneson et al. [49] noted that the delegation of traffic signal maintenance and operations procedures to individual DOT districts may lead to "operational inconsistencies" which, in turn, could increase delays. Devolution is thus within the state DOT, which suggests that devolution can occur without changing the structure of an organization but rather through altering the autonomy of its units. Differences in practices were noted when an MPO (such as that of Kansas City) straddles two states with the degree of project selection authority retained by the MPO varying for projects from each state [29].

\section{(iv) Potential Failure to Share Information}

For example, when an MPO crosses multiple transportation districts (e.g., the Denver, Colorado MPO overlaps with three of the state's six transportation districts [23]) it may be difficult to predict available revenue available to the MPO. Ayers [32] implied that some MPOs simply do not have reliable estimates of revenues that might otherwise appear to be available, noting that "funding estimates are not typically available during the MPO prioritization process."

\subsection{Limitations}

The foregoing discussion of whether it is advantageous to centralize or decentralize authority has three limitations.

\section{(i) Centralized Authority May Not Necessarily Be Used As Intended}

Dempsey et al. [50] explained that MPOs may hesitate to reject undesired projects because of the view that, should this occur, the state could simply spend transportation funds elsewhere. In some instances, the MPO devolves a substantial amount of project selection authority to member jurisdictions, lessening its regional focus. When central authority is lacking, planners have developed ways to accomplish some regional planning. For example, Moscovich [51] identified "coping mechanisms" used in the San Francisco Bay area where localities have different characteristics—urban, suburban, and rural-and, as a consequence, different priorities; for example, "tacticalagreements" (e.g., those where jurisdictions cooperate explicitly to obtain state or federal funds) rather than "strategic agreements" are pursued. The disparity between the Missouri and Kansas programming practices for their shared MPO [29] illustrates the variability in authority allocation among the states. 
(ii) Diminishing Centralized Resources May Reduce the Relevance of

Discussions of Authority

Over the past two decades, the MPOs and states faced declining purchasing power of revenues from the (centralized) Highway Trust Fund. Accordingly, other funding options, such as local sales taxes used by 33 states, become increasingly important. In California, the $1 / 2$ cent sales tax has been reported as being a larger revenue source than combined federal and state revenues [22]. Besides California, 32 other states enable localities to use a local sales tax to raise revenue for highway or transit investments, although in some states only a few counties elect to use this option [52]. Thus, parallel organizations, such as localities, may increase in importance given their access to other funding sources.

\section{(iii) Actual Decision-Making Processes May Differ from Those That Are Documented}

Montes de Oca and Levinson [53] articulated the limitations of a literature review: after examining procedures outlining how the TIP was established and interviewing county, MPO, and state staff, the authors concluded that documentation alone did not fully describe how decisions were made, noting that staff "did not give a clear answer on how projects that are in those official documents get selected."

\subsection{Potential Characteristics of Effective Coordination under Evolution or Devolution}

Often an organization does not have a choice to increase or decrease its authority, rather, political forces may prescribe where such authority is situated. Thus, given the aforementioned advantages and disadvantages of devolved authority, what are some of the characteristics of effective collaboration-regardless of whether authority is centralized or not? Six characteristics emerge based on explicit consideration of these advantages and disadvantages. These characteristics are as follow.

\section{(i) Clear Incentives for Collaboration}

In the centralized case (e.g., an interstate coalition), the I-95 Corridors of the Futures Program, an incentive exists for joining forces-the availability of millions of federal dollars [12, 13]. The collaboration of local jurisdictions cooperating to share funds is another example from a decentralized entity [51].

\section{(ii) Authority}

If incentives alone cannot encourage collaboration, then some implementation mechanism is required to achieve the desired behavior. For example, return to the programming of specific projects; a useful practice is a mechanism to encourage timely local or regional expenditures of funds. Both Missouri (through its "Reasonable Progress Policy" [54]) and California (through a state law [26]) require that suballocated funds be programmed within 1 year. Note that authority can be achieved through not just legal power but through the availability of resources: as shown by RTC in Nevada, the impact of lessening federal funds can be mitigated when localities wish to share their revenue-generation authority with the MPO. 


\section{(iii) Transparency}

For example, one element of decision-making — the selection of projects for funding-should be well documented. This documentation includes written notification for rejected projects and an explanation of how specific measures are used. A general theme noted from a workshop held with nine midwestern states was the need to demonstrate how specific projects were selected [55] with respect to the consultation process. One Florida practice is that if an MPO's project cannot be funded, a written rationale as to why this is the case is provided [33]. Further, although the use of performance measures is increasing, it is less common [56], but not less valuable, to show how specific measures caused a particular project to be selected or rejected. Such transparency can also address the "responsiveness" advantage of decentralization, in that an organization can show why controversial decisions are made, as well as the weakness that sometimes critical information is not shared. New Jersey's incorporation of MPO prioritization scores [37] into programming decisions is another instance of such responsiveness.

\section{(iv) Credibility}

A credible institution is needed to implement cooperation in controversial areas. Burco [57] provided a cautionary statement about placing too much emphasis on cooperation in describing the rise of regional planning in California:

"Much of the goal formulation work of planners in the past has been so general that it was virtually meaningless. If the purpose of transportation goal formulation is to find the lowest common denominator of agreement and thereby avoid controversy, it is not likely to be of much value."

To address Burco's criticism, an institution must have sufficient credibility to address issues that require resolution by a means other than consensus. One element of credibility is that such an institution does not necessarily serve a predefined interest. For example, Lane and Hudson [58] noted that the federal goal of interagency cooperation "is not necessarily served by designating a single regional planning agency as the MPO, which may also have the effect of bypassing state statutory authorities vested in several transportation agencies." While reporting that $79 \%$ of survey respondents reported that, giving MPOs increased project implementation authority would improve transportation planning, GAO [36] noted one response stating that the MPO had greater credibility precisely because the MPO did not have a "stake" in operating a particular transportation mode. Another element of credibility is the entity's institutional memory. For example, placing term limits on elected officials transferred power from those officials to agencies with longer serving staff [59].

\section{(v) Experienced Personnel}

Such personnel cannot only move projects forward but make linkages among diverse areas such as land use, operations, and transportation. For example, consider the linkage between transportation planning and transportation operations: Kozlak [42] noted two advantages (a stronger integration of planning and operations and "more realistic planning") but also a disadvantage (a dominance of operations over planning, especially for transit operations). Given the Las Vegas MPO's responsibility to manage an arterial system, it was feasible for the MPO (1) to identify the benefits of previous local funding initiatives and (2) to recommend 
a new local (voter-approved) funding initiative [35]. Such experiences suggest that, with the right personnel, operations expertise can positively affect programming decisions. However, a caution is that some decisions made by MPOs should perhaps be made by a different entity: Kramer [60] noted that some freight decisions (such as those made by international shippers) belonged at a federal or at least a multistate level whereas other shipment decisions, such as those made by a bakery, belonged at a local level. Experienced personnel can address this decision.

\section{(vi) Ability to Evaluate Tradeoffs}

Consider the efficiency advantage noted for devolving certain projects [40,41] coupled with the loss of network benefits that may result from solely a local perspective [45, 46]. An ideal organization would be able to determine which parts of the network were sufficiently critical to require mustering political or financial capital-in short, the organization would be able to prioritize its efforts. This ability to make tradeoffs would help address the potential weakness of decentralized decisions where, in order to move a project forward, full mitigation of adverse impacts for each entity is required.

The need for elements of these six characteristics-clear incentives for collaboration, authority, transparency, credibility, experienced personnel, and an ability to evaluate tradeoffs-has been made in the context of advancing a large infrastructure project. Giuliano [45] offers the history of California's public-private $32 \mathrm{~km}$ Alameda Corridor rail line which successfully brought eight cities, three railroad companies, two ports, and two regional agencies into sufficient agreement to construct the $\$ 2.4$ billion project. The existence of fragmented power threatened to prevent construction because each entity wielded the ability to stop the project; for example, a city could have refused to allow construction without compensation for adverse impacts (e.g., higher rail volumes and construction noise), or the railroad companies could have refused to sell rights of way necessary for construction. However, the project was ultimately built, with the authority providing mitigation funds to the cities in return for their expedited permits for construction. Giuliano [45] argues that, to achieve this-large scale project within a devolved environment and without increasing costs substantially, several conditions were essential, four of which were experienced personnel (with the requisite technical and organizational skills), an entity with sufficient funding and political power to "buy out" the smaller cities that could otherwise have hindered the project, clear incentives for cooperation (such as economic development, elimination of at-grade rail crossings [61], and added rail capacity [62]), and an understanding of the project's regional benefits.

\section{Case Study: Access Management of the Secondary System}

In addition to infrastructure construction, several other types of initiatives-linkage of operations and maintenance, coordination of transportation and land use, effective emergency response [9], reduction of injuries and societal costs, or provision of mobility for specific population segments-necessitate some element of cooperation. Cooperation may be necessary because no single entity has full purview of a problem's domain; a prime example is highway safety, where countermeasures in the areas of design, enforcement, and driver education are typically shared by DOT, law enforcement, and driver licensing agencies. Cooperation may also become necessary because an agency loses some authority in a specific domain. Access management provides one such example. 


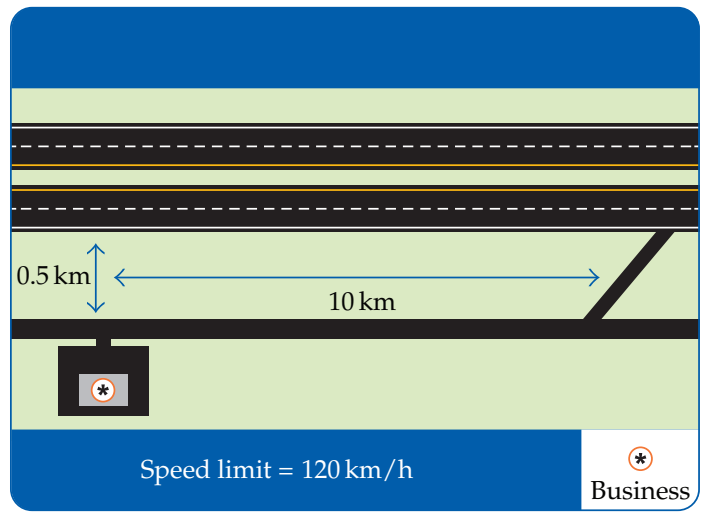

Figure 1: An interstate facility (good mobility, poor access for adjacent landowners).

\subsection{Why Access Management May Be Contentious}

Access management refers to the permitting, design, and spacing of entrances from private property to the highway network and balances two competing functions for a given roadway: mobility for users of the roadway and access for adjacent landowners [63]. A divided interstate highway (Figure 1) provides good mobility for thorough travelers given the high travel speeds and lack of signals and driveways which would impede traffic flow, yet it provides poor access since adjacent landowners may have to travel several kilometers to enter or exit the interstate. By contrast, an undivided arterial facility (Figure 2) provides very good access for adjacent landowners yet relatively poor mobility due to slow travel speeds. These tradeoffs between mobility and access are shown in Figure 3, which is adapted from design guidance provided by the American Association of State Highway and Transportation Officials (AASHTO) (1973) almost four decades ago.

There are at least two situations where access management decisions may be contentious:

(i) when there is not agreement as to whether the facility's primary function is to accommodate mobility (as is the case with interstates) or access (as is the case with local streets), that is, placement of the facility on the curve shown in Figure 3 is not clear,

(ii) when individual developers incur greater costs-in the form of time, land, or construction expenses - to gain access to the roadway network. (e.g., the developer may be required to share entrances or use interparcel connections), that is, movement of the facility to the right in Figure 3 increases the landowner's costs.

\subsection{Why Access Management Merits Consideration as a Case Study}

While any number of transportation initiatives could be considered as a case study, the topic of access management merits attention in a decision-making context for several reasons: it concerns operation of the system, it encompasses multiple areas of authority, it involves the private sector, and it entails tradeoffs as follow. 


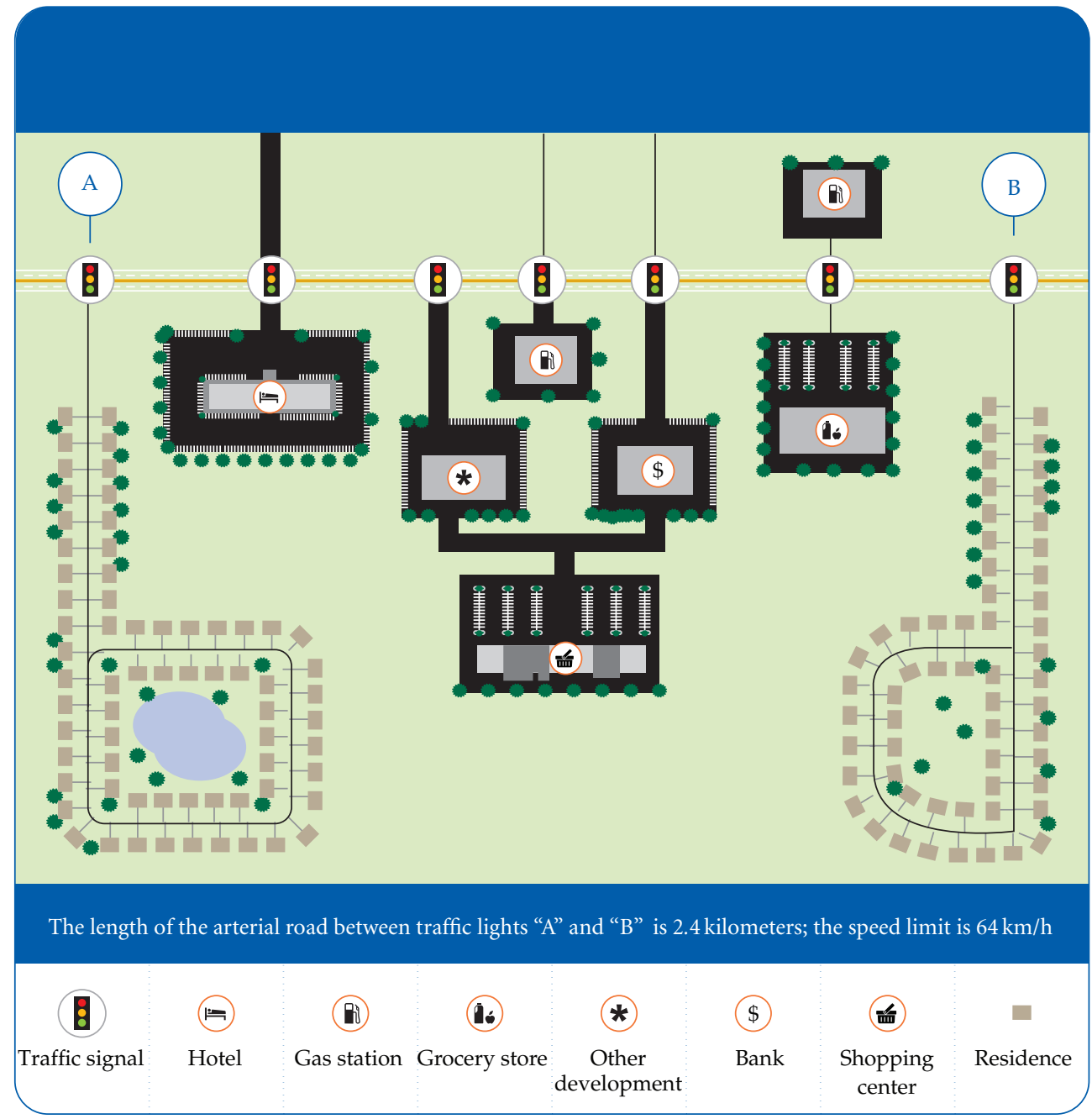

Figure 2: An undivided facility (poor mobility, good access for adjacent landowners).

\subsubsection{Operating the System}

By definition, access management pertains to operating and maintaining the transportation system as opposed to solely constructing new infrastructure per se; thus, it is a topic that is likely to be relevant as available resources for transportation infrastructure investment decline.

\subsubsection{Multiple Areas of Authority}

Access management bisects several areas of public authority: private landowners (since it is often landowners who need new access to a state or municipal highway network), county or city planning boards (who may respond to requests for new development and thus have 


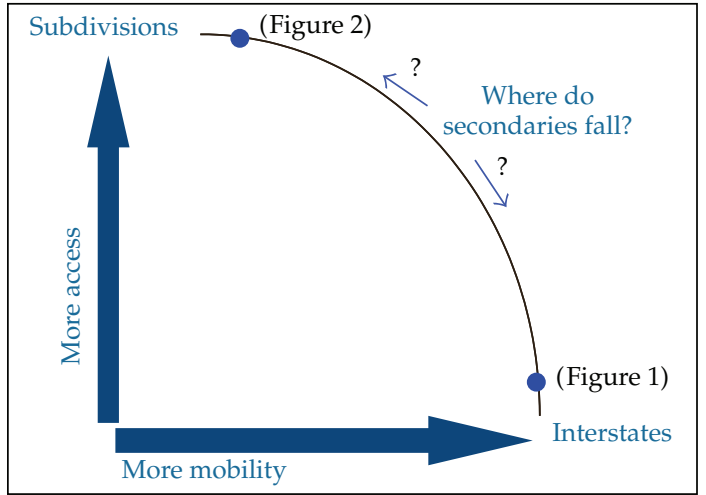

Figure 3: Role of secondary facilities for access management.

purview over local zoning and subdivision ordinances), and transportation agencies (who may be responsible for overseeing the highway network).

\subsubsection{Private Sector Involvement}

Access management also has implications for private sector involvement, both in terms of constructing additional infrastructure as a mitigation measure (when new development is proposed and a rezoning is sought, a landowner may offer to build new infrastructure in conjunction with the rezoning request) and in terms of residential impacts (since the manner in which this new infrastructure is designed affects homeowners). This financial component is not trivial when the role of subdivision streets are considered. At present, secondary facilities include subdivision streets that are incorporated into the state network. The relevance of such facilities may grow in the sense that Gifford and Abdukadirov [64] estimate that, between 2001 and 2005, subdivision streets accounted for more than half of the new lane-km constructed in Virginia for that period, excluding cities plus Arlington and Henrico counties.

\subsubsection{Tradeoffs}

The need for access management is a symptom of the debate concerning transportation networks' role; while each individual access point in Figure 2 provides an immediate benefit to adjacent landowners, it provides an immediate disbenefit to through travelers. Access management, therefore, concerns explicit consideration of such tradeoffs, and local support can be variable. For example, while a review [65] of 59 Virginia county's comprehensive plans found that 35 of these plans support access management in some way (e.g., encouraging interparcel connectivity, discouraging strip development, or suggesting corridor studies), some plans proposed development that might adversely affect good access management (e.g., the addition of interchanges that might not meet AASHTO standards or commercial development near intersections and interchanges).

These four challenges are common to a variety of transportation initiatives, and; thus, lessons learned in this domain may be applicable to other initiatives. 


\subsection{The Context: Solutions to Encourage Better Access Management under Decentralization}

Access management exemplifies a challenge faced by organizations who seek to respond to an evolution or devolution of decision making authority. Consider, for example, the challenges a state like Virginia might consider in responding to access management in a devolved environment where a county elects to take over operational responsibilities for its secondary facilities, which is permitted under \$33.1-84.1 of the Code of Virginia. The six aforementioned characteristics of effective collaboration illustrate some considerations for a state to achieve its aims despite a lack of direct authority.

Conceptually, these may be defined as shown in Table 1, which identifies potential ways to provide incentives to localities for cooperation, such as making cooperation a requirement for grant funding. Some methods in Table 1 may not be feasible in a given state's present environment, such as using a funding formula allocation that incorporates the degree of access management on the secondary system as a factor. However, other methods in Table 1 may be feasible, such as the incorporation of standards into negotiated agreements between the state and localities.

As these characteristics require political, financial, or staff resources for implementation-and as no state has unlimited resources-Table 1 can likely be used only if there is a mechanism for determining which secondaries merit greatest attention. This places an emphasis on the last item for state staff and tangentially matches the benefits others have noted of having operations expertise affect planning decisions [35, 42].

\subsection{A Specific Example of How to Implement Elements of Table 1}

Implementation of Table 1 requires substantial advocacy for access management on behalf of the state. A specific example facing a state may be to modify Figure 2 such that the individual residential developments are connected, which would remove some traffic from the arterial system. Four of the six characteristics - experienced personnel, ability to evaluate tradeoffs, credibility, and clear incentives-are illustrated for this example.

A scenario based on Figure 2 is assumed, where there exists a $2.4 \mathrm{~km}$ segment of an arterial facility; relatively poor access management exists along the corridor as evidenced by the numerous direct access points. While the state controls the arterial facility, the county controls secondary facilities and the land development function. The two residential developments shown near location A and B are not yet built but have been proposed by a developer to the county. The county is aware that the developer will seek to have the roads within the development incorporated into the county system of secondary facilities. Although the state does not control the decisions made by the county, consider actions the state may take to influence operations of the facility.

\section{(i) Experienced Personnel}

Experienced personnel would identify actions that could improve access management along the corridor and evaluate the impacts of these actions. For example, one such action is the construction of a lower-speed facility that parallels the arterial route. (This facility could either (1) connect residential developments A and B near the bottom of Figure 2 or (2) exist as a frontage road near the top of Figure 2.) This facility would divert some, but not all, traffic from the main arterial and would provide some congestion relief. Using methods such as 
Table 1: Possible ways to encourage localities to support access management on the secondary system.

\begin{tabular}{|c|c|}
\hline Characteristic & Potential state mechanism to create the condition \\
\hline Experienced personnel & $\begin{array}{l}\text { Ensure agency staff can assist localities, if so requested by } \\
\text { localities, with (1) identifying ways to implement access } \\
\text { management techniques through the land development process } \\
\text { and ( } 2 \text { ) estimating and reducing the benefits and costs of this } \\
\text { implementation }\end{array}$ \\
\hline Credibility & $\begin{array}{l}\text { Have staff be able to quantify the benefits of access management } \\
\text { at specific locations and show where better access management } \\
\text { can have the greatest impact if resources are limited }\end{array}$ \\
\hline Authority (with sufficient funding) & $\begin{array}{l}\text { Ability to provide grants to locale to perform detailed corridor } \\
\text { studies that identify ways to implement access management on } \\
\text { secondary facilities through the land development process }\end{array}$ \\
\hline Authority (with sufficient power) & $\begin{array}{l}\text { Incorporate into the devolution agreement operational } \\
\text { procedures that keep certain facilities at an agreed-upon } \\
\text { standard. For example, access standards for facilities of type } x \\
\text { must meet those followed by the state DOT for that type of } \\
\text { facility }\end{array}$ \\
\hline Transparency & $\begin{array}{l}\text { Have clear standards for incorporating privately built } \\
\text { subdivision facilities into the state system (or encourage } \\
\text { localities to use such standards if they control such facilities), } \\
\text { where these standards include connectivity of the subdivision } \\
\text { network }\end{array}$ \\
\hline Clear incentives for cooperation & $\begin{array}{l}\text { Funding formula allocation that includes, as a factor, degree of } \\
\text { access management practiced by locale on the secondary system. } \\
\text { This seeks to avoid the use of consensus as the sole criterion for } \\
\text { decision making }\end{array}$ \\
\hline Ability to evaluate tradeoffs & $\begin{array}{l}\text { Ability to identify a limited number of secondary facilities } \\
\text { where access management is critical because the facility offers } \\
\text { statewide or regional, rather than local only, benefits. (A } \\
\text { facility's functional classification, coupled with information } \\
\text { about its relative importance for thorough movements, may help } \\
\text { an agency make such a determination) }\end{array}$ \\
\hline
\end{tabular}

those shown in (6.1), staff might quantify the congestion relief impacts as shown in Table 2, where the local route removes some of the arterial volume, thereby raising speeds on the arterial route

$$
\text { Speed }=\frac{\text { Free flow speed }}{1+.05(\text { Hourly volume } / \text { Capacity })^{10}} .
$$

\section{(ii) Tradeoffs}

Tradeoffs may be estimated by considering the impact of better access management here rather than at other locations. For example, when speeds are below $72.4 \mathrm{~km} / \mathrm{h}$, increasing speeds tend to reduce nitrogen oxide (NOx) emissions and volatile organic compound (VOC) emissions, both of which are precursors to ground-level ozone (see Figure 4). During a single day, with a volume of 27,500 vehicles per day, the conditions in Table 2 suggest a reduction of about $2 \mathrm{~kg}$ of such emissions. However, if volumes were higher (say as much as 32,500 vehicles per day), then the new local facility could help reduce emissions by as much as $14 \mathrm{~kg}$ as shown in Figure 5. Thus, information from Table 2 (in terms of congestion impacts) and 
Table 2: Impact of providing a new local road in Figure $2^{\mathrm{a}}$.

\begin{tabular}{|c|c|c|c|c|}
\hline \multirow[b]{2}{*}{ Hour of the day ${ }^{b}$} & \multicolumn{2}{|c|}{ Without the local route } & \multicolumn{2}{|c|}{ With the local route } \\
\hline & $\begin{array}{l}\text { Arterial volume } \\
\text { (veh/h) }\end{array}$ & $\begin{array}{l}\text { Arterial speed } \\
(\mathrm{km} / \mathrm{h})\end{array}$ & $\begin{array}{l}\text { Arterial volume } \\
(\text { veh/h) }\end{array}$ & $\begin{array}{l}\text { Arterial speed } \\
(\mathrm{km} / \mathrm{h})\end{array}$ \\
\hline 7 a.m.-8 a.m. & 1,928 & 48.8 & 1,879 & 51.5 \\
\hline 8 a.m.-9 a.m. & 2,123 & 34.9 & 1,879 & 51.5 \\
\hline 4 p.m.-5 p.m. & 2,063 & 39.4 & 1,879 & 51.5 \\
\hline 5 p.m.-6 p.m.c ${ }^{c}$ & $2,387^{c}$ & $17.2^{\mathrm{c}}$ & $1,894^{\mathrm{c}}$ & $50.7^{\mathrm{c}}$ \\
\hline
\end{tabular}

${ }^{a}$ Computations used hourly distributions given for major arterial facilities coupled with speed/volume relationships suitable for sketch planning analysis [66] and shown as (6.1); hourly traffic volumes between the main arterial and the local road were balanced such that travel times on the two routes were equivalent. The arterial has a higher free flow speed and practical capacity $(64.4 \mathrm{~km} / \mathrm{h}$ and $1,600 \mathrm{veh} / \mathrm{h})$ than the local road $(51.5 \mathrm{~km} / \mathrm{h}$ and $550 \mathrm{veh} / \mathrm{h})$. It is assumed the local road and the arterial are the same length.

${ }^{\mathrm{b}}$ For example, Table 2 shows that, from 5 p.m. to 6 a.m., there are 2,387 vehicles using the arterial road at a speed of $17.2 \mathrm{~km} / \mathrm{h}$. With a local road available, $493(=2,387-1,894)$ vehicles would use this new local road such that speeds on both the new local road and the arterial facility would be in equilibrium at $50.7 \mathrm{~km} / \mathrm{h}$.

${ }^{c}$ At other hours of the day, volumes are lower such than according to (6.1), the arterial speeds are always higher that the local route speeds.

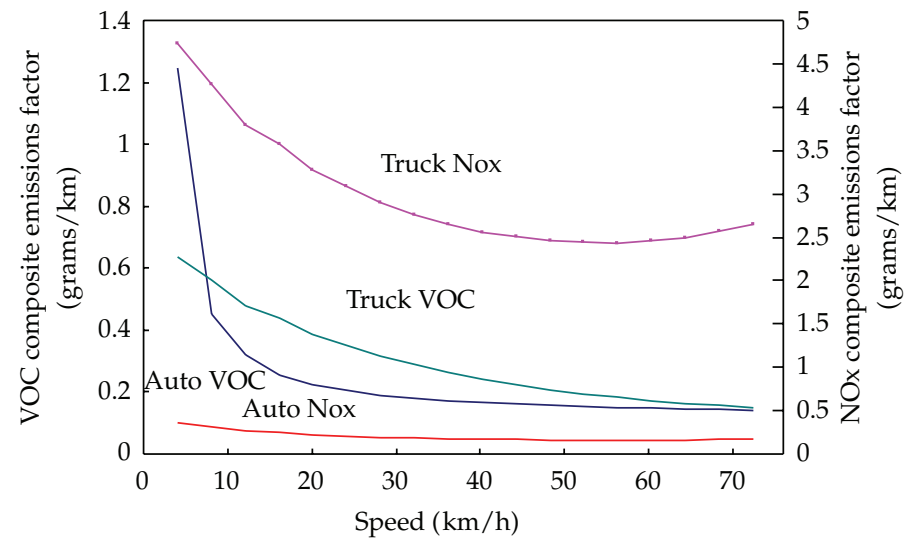

Figure 4: VOC and NOx emissions per vehicle- $-\mathrm{km}$ traveled. Estimated from executing the EPA's MOBILE Emissions Model (version 6.2).

Figure 5 (emissions impacts) may be compared to various facilities and prioritized in terms of which measures may have the greatest effect.

\section{(iii) Credibility}

Credibility may be enhanced by documenting the impact of decisions. For example, the state may encourage the county to use connectivity requirements when deciding whether or not to assume responsibility for maintaining privately built streets. Such requirements may include the extent to which subdivision streets connect to other properties outside the subdivision [67]. For example, the proposed subdivisions in Figure 2 each have one such connection, which is to the arterial only. This connectivity could be increased by directly connecting the two residential areas with the new local route. While increasing this connectivity would benefit operations on the arterial, the developers (and future residents) may object to such connections due to the possibility of increased thorough traffic. Accordingly, planners may use data comparable to that shown in Table 2 (or modified as appropriate to account for 


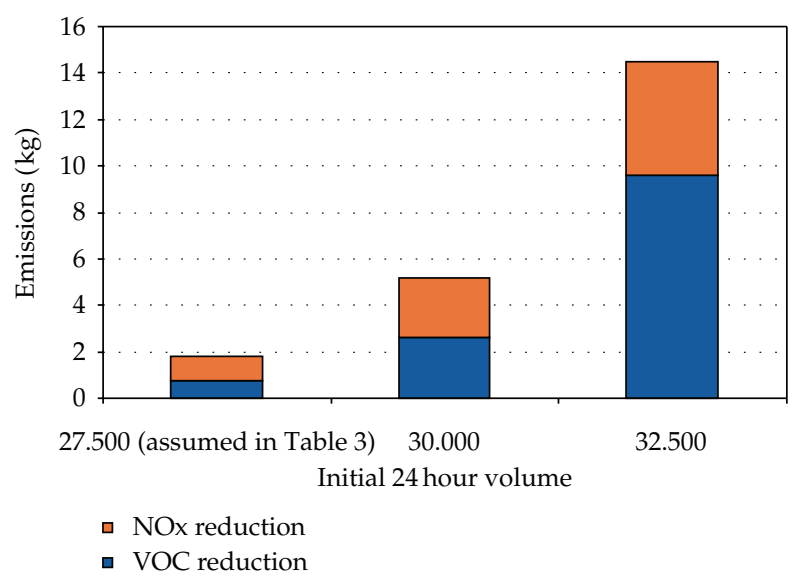

Figure 5: Reduction in emissions attributable to a new local route. (Reductions result because the local route leads to an increase in speeds relative to not having such a route. e.g., with a volume of 27,500 veh/day, Table 2 showed that, from 7 a.m. to 8 a.m., the difference in speeds with and without the local road is about $3 \mathrm{~km} / \mathrm{h}$ - a modest increase in speeds and, hence, a modest reduction in emissions. With a volume of 32,500 veh/day, the difference in speeds with and without the local route is greater, and, hence, the difference in emissions is greater.)

further reduction in speeds on the local route) to demonstrate the utility of connections between properties.

\section{(iv) Clear Incentives for Cooperation Exist}

While Table 1 suggests that one incentive is an ability to provide extra funds in exchange for improved access management, this tactic may not be feasible if the state does not have such resources to offer a county. In that instance, one incentive might be to demonstrate the longterm impact of a given decision. For example, the delay reductions shown in Table 2 may be tabulated for all vehicles; for the volumes shown, these delay reductions would be approximately 300 vehicle-hours per day. This reduction may or may not ultimately be persuasive for persons who would not favor the local route, but it provides a benchmark against which the route's merits may be judged. (Certainly a more traditional incentive would be joint collaboration for the purposes of funding; e.g., such a project might be eligible for CMAQ funds based on its emissions reduction potential.)

In practice, site-specific conditions will influence any computations such as those shown here. For example, other factors affect the traveler's decision to use an alternative route such as perceived travel time, knowledge of the area, and whether there are destinations along the parallel route. Further, the speed/volume delay relationships, such as that shown in (6.1), can vary by location and travel condition; thus, alternative approaches to (6.1) are available.

In this case study, two observations should be noted regarding these characteristics. First, the agency is largely in the role of providing ideas and impacts of those ideas; in a sense, the unifying theme of these characteristics is that the state agency is providing information. Second, the agency is in the position of needing to identify opportunities in an agenda established by others, as opposed to having the power to establish an implementation schedule. That is, rather than developing a grand plan for improving access management, the agency identifies opportunities as they arise; the example in the case study was that of 
the two proposed residential developments necessitating a rezoning from the county prior to their construction. Other opportunities might include a county-led widening of the proposed route (where opportunities to build frontage roads would be examined) or consolidation of existing driveways in concert with a redevelopment of the area. In both instances, the onus is on the state agency to be prepared to identify instances where better access management can be implemented.

\subsection{Extension of the Solutions to Other Areas Where Control Is Decentralized}

Note that the conditions shown in Table 1 may be applied to other potential impacts of devolution. For example, consider heavy truck connectivity: if localities operate their own secondary roads (counties) or their urban system (cities), then these localities may develop their own permitting processes for overweight trucks, meaning such vehicles must obtain permits from each locale through which they travel (Ken Jennings, personal communication, September 11, 2009). Certainly, it is possible that, in the future, obtaining permits from multiple jurisdictions will not be problematic for heavy trucks; for example, overweight trucks must already obtain permits from individual cities if those vehicles will use the urban system. However, it is possible that jurisdictions might adopt different standards such that obtaining permits from multiple jurisdictions, possibly leading to inconsistent truck routes between counties [68] or increased administrative costs substantially for businesses. Under this second scenario, conditions from Table 1 might be adopted as follows.

(1) Experienced Personnel. Ensure the state has sufficiently experienced personnel who can assist localities, if such assistance is desired by localities with aligning the costs of the permit and the damage to the facility.

(2) Credibility. Demonstrate the economic impacts of freight movement; while direct impacts may not be felt at the local level, show how freight influences the state revenues (which are felt at the local level). Coordinate efforts between state staff, localities, and local/state chambers of commerce to ensure that the economic impacts of maintaining a freight network on certain critical facilities is understood.

(3) Transparency. Demonstrate the effects of freight connectivity on congestion in a manner comparable to that shown in Table 2.

(4) Ability to Evaluate Tradeoffs. In concert with item (2), show which sections of the network are most critical for freight movements and which can be left completely to localities with minimal adverse freight impacts.

(5) Clear Incentives for Cooperation. Provide grants or other financial assistance to certain localities to enable them to adopt consistent standards for accommodating overweight trucks.

(6) Authority. Maintain an office at the state level that is able to administer technical and financial assistance to localities as part of item (1) above.

\section{Conclusions}

In 2003, Altshuler and Luberoff [69] offered a more "nuanced" viewpoint in response to the argument that the era of large-scale infrastructure investments was over. Although recognizing emergent constraints since the 1960s-limited public funds, increased legislative and judicial support for environmental values, and greater local roles-they provided examples of air, highway, and rail transit "megaprojects" built since 1970, noting that an essential element 
had been business community support. While not tracking business involvement directly, a comparable observation is that many of the implemented initiatives cited in this paper $[35,39-43,45]$ included a strong ability to identify benefits widely understood by diverse stakeholders.

(i) It is plausible but not certain that, in the future, planning will be conducted at multiple administrative levels of government-more so than is the case at present. This expectation arises because of two opposing forces. One force is greater devolution of some responsibilities from the state level to the local level. The other force is that there may be growth in multistate coalitions [11,39]. Advantages, such as greater responsiveness to localities [40], and disadvantages, such as adverse network impacts [45], have been noted.

(ii) Such planning at multiple administrative levels contributes to variations in practice. For example, there is substantive variation regarding how states currently allocate programming authority among the state agencies, MPOs, and localities. This finding is not surprising given that devolving decision authority has both advantages and disadvantages and that other factors, such as alignment of civil boundaries, differ by location.

(iii) If transportation decision making is increasingly dispersed among multiple entities, the literature [45] suggests it may be challenging to implement projects that either (1) offer well-understood network benefits but not a local benefit or (2) do not mitigate all adverse impacts for all entities. A step that may address these challenges is to identify which "parts" of the transportation system have statewide as opposed to only local benefits such that coordination efforts (e.g., negotiated agreements with localities) can be concentrated on those system parts.

(iv) Six practices that may enhance collaboration in a decentralized environment are transparency, credibility, authority, experienced personnel, incentives for collaboration, and an ability to evaluate tradeoffs. Respective examples of these practices include documenting the project selection process, using an organization that does not have a vested interest in a particular mode to make programming decisions, implementing administrative mechanisms to encourage the timely expenditure of funds, using operational expertise at the programming stage, and cogently communicating project benefits especially for the network critical projects. The poignant reminder noted by Burco [57] which is that seeking consensus does not equate with removing areas of controversy-suggests an emphasis is needed on being able to discern and articulate long-term project benefits and costs. To do so in an accurate manner is quite difficult but is also, perhaps, suitable as a long-term goal.

(v) The case study shows that, in a devolved environment, agencies must be ready to respond to opportunities. This does not mean that agencies are reactive-staff must be ready to develop details such as those shown in the case study—but, rather, agencies must be alert for opportunities. Thus, the six characteristics are those that agencies which lack direct authority want to be ready to deploy.

\section{Acknowledgments}

Insights and assistance from Tom Biesiadny, Ralph Davis, Linda Evans, Katherine Graham, Robert Perry, Mary Lynn Tischer, and two anonymous reviewers were helpful in developing this paper. The author alone is responsible for its contents.

\section{References}

[1] W. J. Mallet, “Metropolitan transportation planning," Report R41068, Congressional Research Service, Washington, DC, 2010, 2010, http://assets.opencrs.com/rpts/R41068_20100203.pdf. 
[2] P. Gordon, "The false promise of regional governance and regional planning," in 21st Century Highways, W. Cox, A. Pisarski, and R. D. Utt, Eds., pp. 149-162, Heritage Foundation, Washington, DC, USA, 2005.

[3] P. G. Lewis and M. Sprague, Federal Transportation Policy and the Role of Metropolitan Planning Organizations in California, Public Policy Institute of California, San Francisco, Calif, USA, 1997, http:// www.ppic.org/content/pubs/report/R_497PLR.pdf.

[4] Virginia Department of Transportation, Local Assistance Division, "Urban Construction Initiative (First Cities)," Richmond, Va, USA, 2009, http://www.virginiadot.org/business/local-assistancefirstCities.asp.

[5] P. E. Canning, E. E. Hellawell, S. J. Hughes, B. C. M. Gatersleben, and C. J. Fairhead, "“'Devolution” of transport powers to Local Government: impacts of the 2004 Traffic Management Act in England," Transport Policy, vol. 17, no. 2, pp. 64-71, 2010.

[6] Office of Intermodal Planning and Investment, "Virginia's Long-Range Multimodal Transportation Plan," Richmond, Va, USA, 2010, http:/ / www.vtrans.org/vtrans2035_final_report.asp.

[7] J. Miller, "Institutional Changes in Transportation Decision Making," Prepared for the Office of Intermodal Planning and Investment, Richmond, Va, USA, 2009, http:/ / www.vtrans.org/resources / VTrans2035_Decisionmaking_FINAL.pdf.

[8] K. C. Sinha and S. Labi, Transportation Decision Making, John Wiley \& Sons, Hoboken, NJ, USA, 2007.

[9] M. D. Meyer and E. J. Miller, Urban Transportation Planning: A Decision-Oriented Approach, McGraw Hill, New York, NY, USA, 2nd edition, 2001.

[10] D. L. Roth and R T. Aggarwala, "Whose Railroad is this, anyway? Opportunities and challenges in regionalizing the northeast corridor," Transportation Research Record, vol. 1785, pp. 1-9, 2002.

[11] A. A. Amekudzi, L. Thomas-Mobley, and C. Ross, "Transportation planning and infrastructure delivery in major cities and megacities," Transportation Research Record, vol. 1997, pp. 17-23, 2007.

[12] Corridors of the Future, "FHWA, U.S. Department of Transportation," 2009, http://www.corridors dot.gov/.

[13] "Corridors of the Future Development Agreement Between the United States Department of Transportation and the Florida Department of Transportation, the Georgia Department of Transportation, the South Carolina Department of Transportation, the North Carolina Department of Transportation, the Virginia Department of Transportation for the Interstate 95 Corridor of the Future," 2009, http:/ / www.virginiadot.org/news/resources/Statewide/95DevelopmentAgreement.pdf.

[14] "Memorandum of Understanding: I-81 Regional Commerce Corridor," http://www.virginiadot.org/ projects / resources/I-81MOUoctober08.pdf.

[15] J. L. Oberstar, J. L. Mica, P. A. DeFazio, and J. J. Duncan Jr., “U.S. House of Representatives, Committee on Transportation and Infrastructure. The Surface Transportation Authorization Act of 2009: A Blueprint for Investment and Reform," Washington, DC, USA, 2009, http:/ /www.ampo.org/ assets/816_blueprint.pdf.

[16] U.S. House of Representatives, Committee on Transportation and Infrastructure, "The Surface Transportation Authorization Act of 2009 [Proposed Reauthorization]," Washington, DC, USA, 2009, http:/ / www.ampo.org/assets/818_surfacetransportatonact20.pdf.

[17] J. W. Fischer, R. S. Kirk, W. J. Mallett et al., Surface Transportation Reauthorization Legislation in the 111th Congress: Summary of Selected Major Provisions, Congressional Research Service, Washington, DC, USA, 2009, http://www.itsa.org/files/pdf/ReauthMajorProvisions.pdf.

[18] R. Puentes and L. Bailey, Improving Metropolitan Decision Making in Transportation: Greater Funding and Devolution for Greater Accountability, The Brookings Institution, Washington, DC, USA, 2003, http:// www.brookings.edu/ /media/Files/rc/reports/2003/10transportation_puentes/200310_Puentes .pdf.

[19] J. McKenzie, "The state of the MPO," in The Metropolitan Planning Organization, Present and Future. Conference Proceedings 39, pp. 8-11, Transportation Research Board of the National Academies, Washington, DC, USA, 2007.

[20] Virginia Railway Express, "About VRE," Alexandria, Va, USA, 2009, http://www.vre'.org/about/ company/nvtc-prtc.html.

[21] "The Transportation Planning Process Key Issues," FHWA and FTA, U.S. Department of Transportation, 2007, http:/ / www.planning.dot.gov/documents/briefingbook/bbook_07.pdf.

[22] California Association of Councils of Governments, "CALCOG Guide to Regional Planning as Revised by SB 375," Sacramento, Calif, USA, 2009, http://www.calcog.org/events/documents/ calcogguide.pdf.

[23] G. C. Sciara and M. Wachs, "Metropolitan transportation funding: prospects, progress, and practical considerations," Public Works Management E Policy, vol. 12, no. 1, pp. 378-394, 2007. 
[24] Cambridge Systematics, Inc., Transmanagement, Inc., Transtech Management, Inc. and K. Heanue, "Guidebook for freight policy, planning, and programming in small- and medium-sized metropolitan areas," NCHRP Report 570, Transportation Research Board of the National Academies, Washington, DC, USA, 2007, http:/ /Onlinepubs.Trb.Org/Onlinepubs/Nchrp/Nchrp_Rpt_570.Pdf.

[25] Caltran, "Transportation Funding in California," Sacramento, Calif, USA, 2008, http://www.dot .ca.gov/hq/tpp/offices/ote/fundchrt_files/Trans-Funding-in-California-2008.pdf.

[26] D. G. Murray and C. R. Birner, "Using a transportation improvement program database and a partnership approach to improve project delivery," Transportation Research Record, vol. 1685, pp. 99102, 1999.

[27] North Carolina Association of MPOs, North Carolina Department of Transportation, and North Carolina Association of Rural Planning Organizations, "Achieving a Seamless Transportation System for North Carolina: A Framework for Collaboration," Raleigh, NC, USA, 2005, http:// www.ncdot.org/doh/preconstruct/tpb/PDF/framework_for_collaboration.pdf.

[28] Iowa Department of Transportation, "Guidelines for Development of the Iowa Statewide Transportation Improvement Program (STIP)," Ames, Iowa, USA, 2004, http://ntl.bts.gov/lib/12000/ 12600/12626/stip_guidelines_jan2004.pdf.

[29] L. Goode, J. S. Milazzo, J. B. McCurry et al., "Analysis of the Governance of Metropolitan Planning Organizations (MPOs) in the United States for Potential Application to North Carolina," Institute for Transportation Research and Education, North Carolina State University, Raleigh, NC, USA, 2001, http:/ / www.ncdot.org/doh/preconstruct/tpb/research/download/PPF-0100FinalReport.pdf.

[30] Maryland Department of Transportation, "2010 Statewide Transportation Improvement Program," Hanover, Md, USA, 2009, http://www.mdot.maryland.gov/Planning/STIPandTIP /2010_STIP_Index/2010_STIP.pdf.

[31] Hagerstown-Eastern Panhandle Metropolitan Planning Organization, "FY 2010-2013 Draft Transportation Improvement Program," Hagerstown, Md, USA, 2009, http://www.hepmpo.net/PDF/ Draft1\%20FY\%202010-2013\%20TIP4-29-09.pdf.

[32] L. Ayers, "Programming for transportation: one MPO's experience," in Conference Proceedings 43: Key Issues in Transportation Programming, pp. 19-20, Transportation Research Board of the National Academies, Washington, DC, USA, 2008, http://onlinepubs.trb.org/onlinepubs/conf/CP43.pdf.

[33] Florida Senate Committee on Transportation, "Development of the Florida Department of Transportation's 5-Year Work Program," Issue Brief 2009-334, October, 2008, http://archive.flsenate .gov/data/Publications/2009/Senate/reports/interim_reports/pdf/2009-334tr.pdf.

[34] Nevada Department of Transportation, "Program Development Manual," Carson City, Calif, USA, 2005, http://www.nevadadot.com/reports_pubs/program_development/.

[35] B. H. Hoeft, "MPOs as operating agencies: the Southern Nevada experience," in The Metropolitan Planning Organization, Present and Future. Conference Proceedings 39, pp. 45-46, Transportation Research Board of the National Academies, Washington, DC, USA, 2007.

[36] Government Accountability Office, Metropolitan Planning Organizations: Options Exist to Enhance Transportation Planning Capacity and Federal Oversight, Washington, DC, USA, 2009, http://www.gao .gov/new.items/d09868.pdf.

[37] M. L. Stout, “Negotiated capital programming in New Jersey,” Transportation Research Circular 465, Transportation Research Board of the National Academies, Washington, DC, USA, 1996.

[38] California Transportation Commission, "2007 California Regional Transportation Plan Guidelines," 2007, http://www.dot.ca.gov/hq/tpp/offices/orip/rtp/index_files/2007_California_Regional_ Transportation_Plan_Guidelines.pdf.

[39] C. L. Ross, J. Barringer, J. Yang et al., "Megaregions: Literature Review of the Implications for U.S. Infrastructure Investment and Transportation Planning," Publication FHWA-BAA-HEPP02-2007. FHWA, U.S. Department of Transportation, 2008, http://www.fhwa.dot.gov/Planning/ megaregions.pdf.

[40] F. Whitley, "Virginia's first cities initiative: allowing cities to manage their own state urban road construction programs," APWA Reporter, vol. 73, no. 6, pp. 26-27, 2006.

[41] K. K. Seefeldt, S. W. Adams, H. O. Hollimon, J. T. Holland, T. H. Muehlenbeck, and L. B. West, “Report of the Local Government Advisory Committee to the Commission on Transportation in the TwentyFirst Century," Richmond, Va, USA, 1987.

[42] M. C. Kozlak, "The future of MPOs: MPOs combined with operations and management-the Twin cities experience," in The Metropolitan Planning Organization, Present and Future. Conference Proceedings 39, pp. 44-45, Transportation Research Board of the National Academies, Washington, DC, USA, 2007.

[43] Joint Legislative Audit and Review Commission, "State/Local Relations and Service Responsibilities: A Framework for Change," Senate Document No. 37. Richmond, Va, USA, 1992. 
[44] C. K. Rylander, "Paving the Way: A Review of the Texas Department of Transportation," Austin, Tex, USA, 2001, http://www.cpa.state.tx.us/txdot/txdot405.html .

[45] G. Giuliano, "The changing landscape of transportation decision making," Transportation Research Record, vol. 2036, pp. 5-12, 2007.

[46] J. E. W. Yusuf, L. O'Connell, M. Hackbart, and C. Wallace, "An empirical examination of the statutory characteristics and effects of highway and transportation commissions on DOT capital management capacity," Public Works Management E Policy, vol. 12, no. 3, pp. 533-543, 2009.

[47] J. Mason, "Transportation planning and programming: challenges and implications," in Key Issues in Transportation Programming. Conference Proceedings 43, pp. 67-68, Transportation Research Board of the National Academies, Washington, DC, USA, 2008, http://onlinepubs.trb.org/ onlinepubs/conf/CP43.pdf.

[48] U.S. Department of Transportation, Maritime Administration, "Report to Congress on the Performance of Ports and the Intermodal System," Washington, DC, USA, 2005, http://www.marad. .dot.gov/documents/Rpt_to_Congress-Perf_Ports_Intermodal_Sys-June2005.pdf.

[49] J. Bonneson, S. Sunkari, and M. Pratt, Traffic Signal Operations Handbook, Texas Transportation Institute, College Station, Tex, USA, 2009, http://tti.tamu.edu/publications/catalog/record/?id=31022.

[50] P. D. Dempsey, A. Goetz, and A. Larson, "Metropolitan planning organizations: an assessment of the transportation planning process: a report to congress," University of Denver, 2000, http:/ / www.du.edu/transportation/images/pdfs/Vol_I_Sec_II.pdf.

[51] J. L. Moscovich, "Regional versus county investments," in Key Issues in Transportation Programming. Conference Proceedings 43, pp. 36-37, Transportation Research Board of the National Academies, Washington, DC, USA, 2008, http://onlinepubs.trb.org/onlinepubs/conf/CP43.pdf.

[52] Cambridge Systematics, Mercator Advisors, A. E. Pisarski, and M. Wachs, "Future Financing Options to Meet Highway and Transit Needs," NCHRP Web-Only Document 102. Transportation Research Board of the National Academies, Washington, DC, USA, 2006, http://onlinepubs. trb.org/onlinepubs/nchrp/nchrp_w102.pdf.

[53] N. Montes de Oca and D. Levinson, "Network expansion decision making in Minnesota's twin cities," Transportation Research Record, vol. 1981, pp. 1-11, 2006.

[54] Missouri Department of Transportation, "2007-2011 Statewide Transportation Improvement Program," Jefferson City, Mo, USA, 2006, http://www.modot.mo.gov/plansandprojects/construction_ program/STIP2007-2011/Suballocated.pdf.

[55] American Association of State Highway and Transportation Officials, "AASHTO/NACo/NADO Midwest Local Consultation Workshop," Washington, DC, USA, 2007.

[56] J. Kramer and E. A. Mierzejewski, The 2002 Review of Florida's Twenty-Five Long Range Transportation Plans, Center for Urban Transportation Research, Tampa, Fla, USA, 2002, http:/ / www.dot.state.fl.us / research-center/Completed_Proj/Summary_PL/FDOT_BC353_25_rpt.pdf.

[57] R. A. Burco, "Legislative perspectives on the state transportation planning process and transit planning in California," Transportation Research Record, vol. 563, pp. 13-21, 1976.

[58] J. S. Lane and K. E. S. Hudson, "Organization for regional community participation: the Boston approach," Transportation Research Record, vol. 654, pp. 6-11, 1977.

[59] S. Paine, "Local official's perspective-Tampa, Florida," in Conference Proceedings 43: Key Issues in Transportation Programming, p. 10, Transportation Research Board of the National Academies, Washington, DC, USA, 2008, http:/ / onlinepubs.trb.org/onlinepubs/conf/CP43.pdf.

[60] J. Kramer, National Metropolitan Planning Organization Peer Exchange Proceedings, Transportation Research Board of the National Academies, Washington, DC, USA, 2004, http:/ /onlinepubs.trb.org/ onlinepubs/circulars/ec066.pdf.

[61] T. Judge, "Alameda Corridor shows how its done," Railway Track and Structures, vol. 98, no. 11, pp. 22-25, 2002.

[62] Alameda Corridor Transportation Authority, "Alameda Corridor Fact Sheet," Carson, Calif, USA, 2009, http:/ / www.acta.org/projects / projects_completed_alameda_factsheet.asp.

[63] J. Gluck, H. Levinson, and V. Stover, "Impacts of access management techniques," NCHRP Report 420, National Cooperative Highway Research Program, Washington, DC, USA, 1998.

[64] J. Gifford and S. Abdukadirov, "Private sector investment in roads and streets as a byproduct of the development process," in The U.S.: The Virginia Experience, Transportation Research Board Annual Meeting, Washington, DC, USA, 2007.

[65] M. C. Grimes, "An evaluation of county comprehensive plans in Virginia," VTRC 07-R6, Virginia Transportation Research Council, Charlottesville, Va, USA, 2006, http:/ /www.virginiadot.org/vtrc/ main/online_reports/pdf/07-r6.pdf. 
[66] Systems Applications International, Inc., "Development of methodology for estimating VMT weighting by facility type," EPA420-R-01-009, U.S. EPA, Washington, DC, USA, 2001, http://www .epa.gov/oms/models/mobile6/r01009.pdf.

[67] Virginia Department of Transportation, "Secondary Street Acceptance Requirements, VDOT Internal Training," Richmond, Va, USA, June 2009, http://www.virginiadot.org/projects/resources/SSAR/ 070609_June_Training_June_10.pdf.

[68] Joint Legislative Audit and Review Commission, "State/Local Relations and Service Responsibilities: A Framework for Change," Senate Document No. 37, Richmond, Va, USA, 1992.

[69] A. Altshuler and D. Luberoff, Mega-Projects: The Changing Politics of Urban Public Investment, Brookings Institution Press, Washington, DC, USA, 2003. 


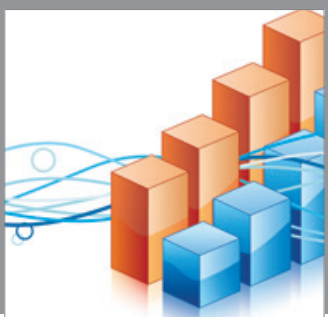

Advances in

Operations Research

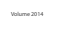

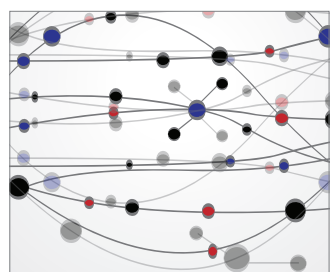

\section{The Scientific} World Journal
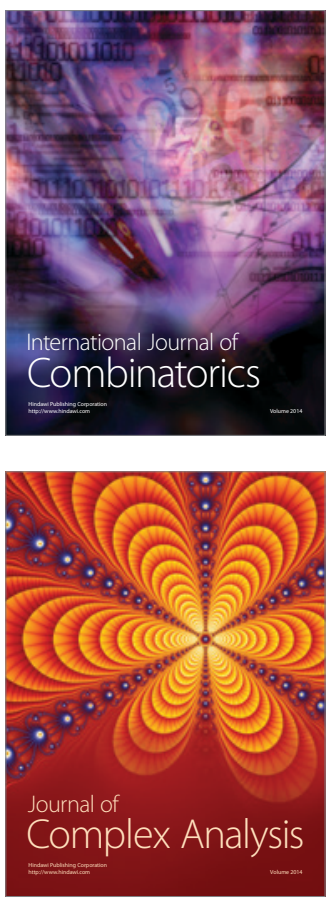

International Journal of

Mathematics and

Mathematical

Sciences
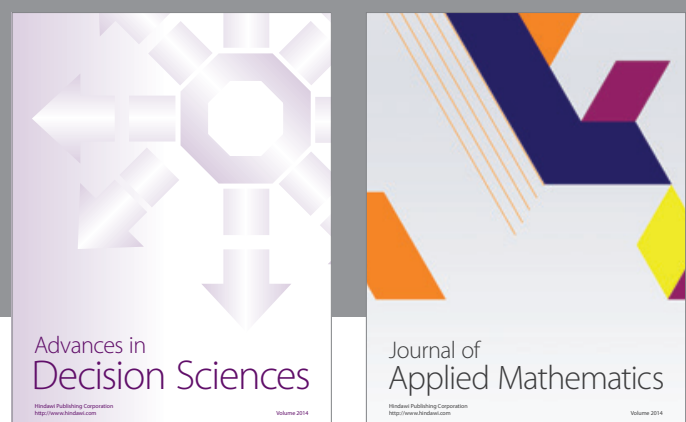

Journal of

Applied Mathematics
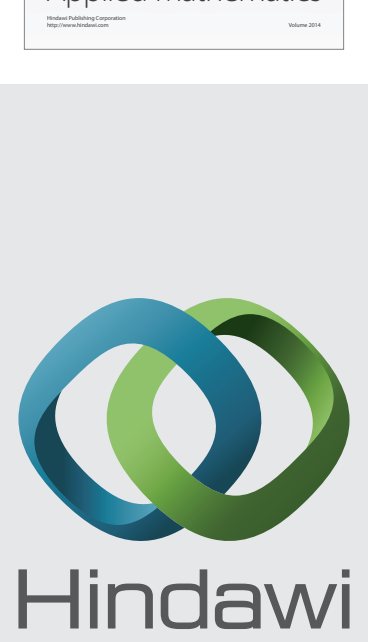

Submit your manuscripts at http://www.hindawi.com
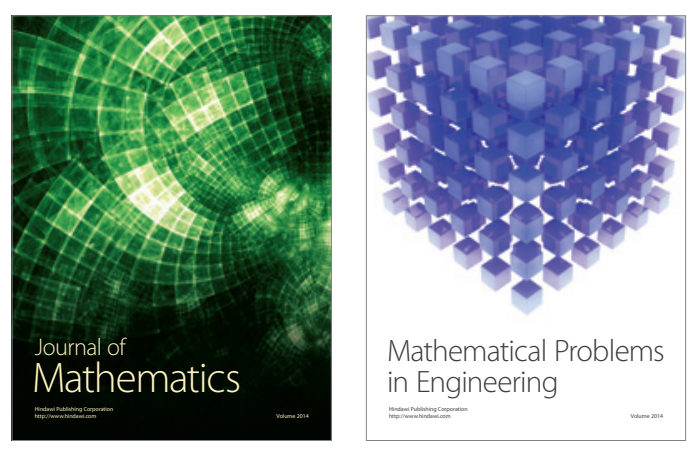

Mathematical Problems in Engineering
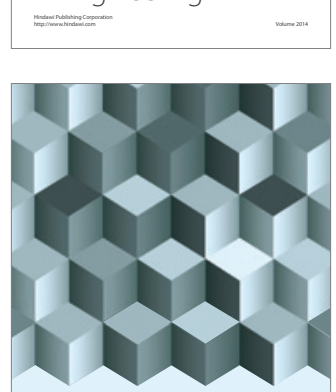

Journal of

Function Spaces
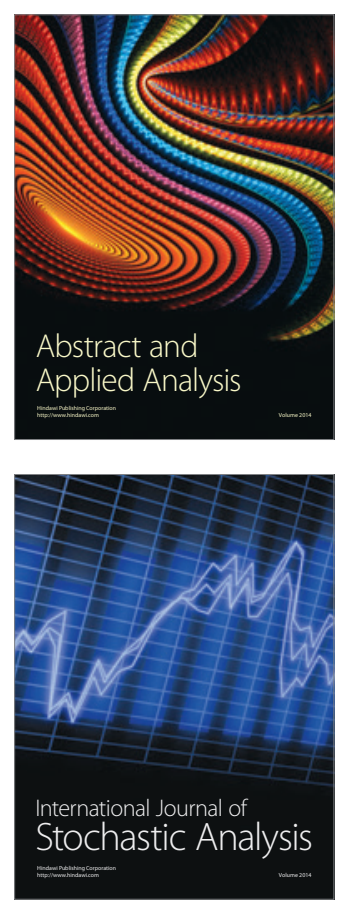

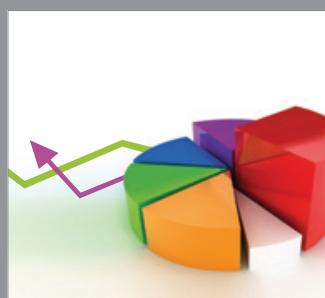

ournal of

Probability and Statistics

Promensencen
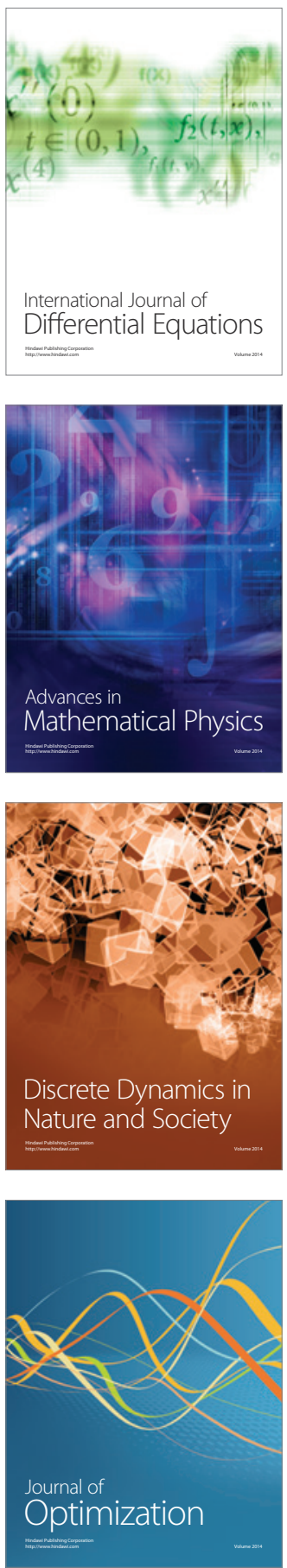